\title{
Developing a Collaborative Culture in on-Line Learning
}

\author{
Peggy B. Gill, Ross B. Sherman, and Genie B. Linn
}

\begin{abstract}
Collaboration is identified as an essential skill for educational leaders in K-12 institutions. As programs for principal preparation move to the online environment, it is essential to develop ways to encourage and facilitate collaboration and cooperation. We will discuss several ways to incorporate collaborative processes in online learning as leaders seek meaningful feedback from peers, problem solve in case study discussions and work through decision making as a collaborative activity.
\end{abstract}

Index Terms - Collaboration, e-learning, leadership.

\section{INTRODUCTION}

Effective school leadership is seen as a key to school improvement [1]. Research is emerging about educational leaders who successfully change districts and schools. Much of this research builds on earlier research about leadership. Most agree that good leaders are both leaders and managers of the school. As leaders and managers, they balance the need for task accomplishment with consideration for stakeholders. As Hoy and Brown (1988) found "a large body of research on schools has consistently demonstrated that the most effective leader behavior is strong in both initiating structure and consideration" (p. 27) [2]. Successful leaders focus on both the "what" of leadership and the "how" of leadership.

It is the leader's vision that guides both these processes. A successful change leader has a clear vision of the goals that must be accomplished to effectively move the school or district toward successful student achievement. The vision serves as the guide by which all actions are judged. This vision is foundational to creating a school plan for improvement [3].

However, this vision must be a vision that is accepted and shared by the stakeholders in the schools. Teachers see the vision as a way to change classroom practice, implement new programs. In addition, the teachers' vision includes a participatory culture in which their ideas and concerns are addressed cooperatively and collectively. Thus, the principal's vision that may focus on more general and broad goals must join with the teachers' vision that focuses on specifics for student learning in a collaborative culture.

Online classes were not originally developed as collaborative endeavors. The first online classes were designed from a lecture model and students had little if any engagement with other students in the class. The online environment developed as a response to student need for

Manuscript received January 15, 2013; revised March 29, 2013.

Peggy B. Gill, Ross B. Sherman, and Genie B. Linn are with the Department of Educational Leadership at the University of Texas at Tyler, USA (e-mail pgill@uttyler.edu, rsherman@uttyler.edu, glinn@uttyler.edu). learning that fit into a busy life, and a less expensive way to attend college. However, as learning platforms emerged there was not a revolutionary change in education. The platforms of the ' 90 's were very teacher centered and did not revolutionize learning. Only as technology advanced did educators begin to recognize the multiple advantages of the online environment. Students could explore topics through lecture, videos and virtual worlds. As online learning evolved, multiple ways of working collaboratively were added to the platforms. However, these collaborative tools were added to enhance learning about the subjects under study, not as an end, in and of themselves. Students were encouraged to discuss course material, work in groups to accomplish learning tasks and generally work in the same ways they would if in a face-to-face environment. As educational leadership programs moved to the online environment in response to student demand, concern was expressed about teaching the "soft skills" of leadership.

Leadership is a relational process [4]. The ability to work with and inspire others has been explored as a leadership essential in numerous studies. A 2006 study found that three skill areas are frequently deficient in beginning leaders: the ability to collaborate effectively with others, critical thinking skills and the ability to communicate effectively with all stakeholders [5]. Daniel Goldman, a noted expert in the field of emotional intelligence, suggests that an experiential approach to learning is needed to develop the soft skills of leadership [6].

The following is a description and discussion of three specific course processes in online instruction that build needed skills in collaboration, critical thinking skills and the ability to communicate effectively. Students spend a semester working through each of the processes.

\section{ACtion RESEARCH AND THE PROCESS OF COLLABORATION}

The complex nature of leading schools means that the principal's job cannot be done single-handed. There is more work than any single person can accomplish and more to know than any one person can know. In short, it takes a whole community--the professional learning community-- to raise a school. Building that community is not easy. It takes hard work, determination, patience, humility, and faith in others.

Principal preparation programs must ready future administrators to solve problems in a way that engages all stake-holders in a culture of continuous improvement. Action research is both a valuable learning tool for principal professional growth and a strategy for school improvement [7]. Consequently, guiding aspiring administrators through an action research project is a relevant and meaningful 
learning experience.

A hallmark of quality graduate programs is the production of a significant professional research project. Action research is the natural direction for graduate students of educational leadership. The Department of Educational Leadership at The University of Texas at Tyler has incorporated the action research experience and the consequent production of a significant research paper into the program requirements. This is accomplished over three semesters and within one content course and a principal practicum; all of which occur on-line in the electronic classroom.

Since both the research process and the writing process are most effectively applied within a collaborative setting, these courses maximize preparation for future administrators by shaping learning experiences within a collaborative environment. The initial content course leads students to identify and investigate an issue on their campus in order to understand and seek solutions for the problem. Since adult learners need opportunities to inquire, reflect, and dialogue with others [8], the first course directs the students through various strategies to support these learning needs. During this first semester of study, the students are equipped with knowledge and skills that support collaboration and given repeated opportunities for practice and implementation. When the practicum course ensues in the final semester, the learners must assume responsibility for completing the research and writing tasks by self-organizing and self-regulating in an asynchronous environment. They are empowered while challenged to lead themselves and work with others to accomplish the research task.

Upon entry into the program students begin communicating immediately with each other on the discussion boards, as they are required to self-organize into learning groups of common interests. This initial task is designed to force students to navigate the system in a way that requires individual initiative and collaboration. These same concepts permeate each learning module. Each learning module contains a peer review activity and culminates in a group reflective dialogue: How did we do as a group? What did we learn? What questions do we have?

In order to be successful in the collaborative process: a) students must be equipped with implementation skills and strategies, b) they must communicate clearly and consistently, c) they must assume personal leadership responsibilities to both guide the group learning as a project manager and participate fully as a group member, d) they must be trustworthy and trust others. Within the collaborative process, aspiring leaders are empowered to construct their own meaning and learning mirroring the constructivist learning of real life in the learning communities [9].

\section{CASE ANalysis For Collaboration}

Case studies build a bridge between theory and practice and allow students to examine multiple points of view. While case studies were originally used extensively in medicine and law, they work equally as effectively in programs for the development of educational leaders. Case studies provide opportunities for students to develop problem solving skills and decision-making skills. When used as a group activity in which the group must not only analyze the case under consideration, but also arrive at a joint decision, the case study also facilitates the development of collaboration and cooperation. Thus, the goal of the case study activity is not arriving at a particular answer or finding a pre-determined "best" action, but learning to listen to the ideas of others, communicate one's ideas effectively and work collaboratively. Case studies also force students to apply the knowledge of leadership principals to the evaluative skills needed in the case study [10].

Students are presented with 10 different case studies over the course of the semester. Each case study presents a short vignette that explores the reality of leadership on a school campus. Students are divided into small discussion groups of 6-10 students. Each student must identify the significant issues in the case study and suggest 3 things that must be done immediately to correct the problem or address the issue presented. For students just beginning the study of leadership, this is very challenging. Their natural inclination is to analyze the case study, tell what went wrong and then say not to do that again. To ask them to shift to the position of "fixer" of the problem is quite difficult. As beginning leaders they approach leadership as a clear action-reaction process and fail to grasp the complexity and non-linearity of leadership. It may take several re-starts before a student and or a group can accept that this problem has occurred and he cannot redo the situation and must live with that situation and find a way forward.

This struggle to find a way forward after a problem has occurred that sets the stage for collaboration. Multiple ideas are suggested as the group seeks common ground. Some ideas are rejected, some are accepted, and some are seen as good ideas but not used. Students learn to find the best decisions possible given the realities of their situation.

The online environment provides an excellent opportunity to practice "listening" skills. Because students type their ideas on a discussion board and must respond to every idea presented, students have built-in reflection time. They must consider every idea presented and provide informative feedback on that idea. Listening becomes an attitude of awareness of the ideas of others. A leaders' success is often predicated upon their ability to listen and understand others' viewpoint [11]. The online environment creates the "wait time" that avoids leadership domination of all discussions.

\section{Decision Making as a Collaborative Process}

Over the past 20 years, the educational system in the United States has been evolving from a largely centralized decision-making structure to a more decentralized one. School based management is referred to in the literature by a variety of terms such as decentralization, restructuring, site-based management, school-based management, participatory decision-making, and school-based autonomy [12].

Irrespective of the term used, the school takes center stage. This shift to school-based management requires fundamental changes to the organizational structure of the district as well as the roles within the organization. Thus, the school principal's role has evolved from one of sole authority in 
decision making to one of collaboration with others.

However, as with any skill, collaboration must be taught and modeled for students. Therefore, it is incumbent upon educational leadership programs to provide students' opportunities to participate in and reflect on site-based decision-making experiences as part of their formal preparation.

In the Principal ship program at the University of Texas at Tyler students are provided the opportunity to work in site-based decision-making groups. Group experiences are delineated into in-basket simulations and assignments that replicate opportunities they will encounter in the future as a principal.

In-basket simulations exemplify the types of problems the principal encounters in the management of his/her school. Problems require the site-based decision making group to apply problem solving skills. Typically there are no right and wrong answers, and groups discuss the pros and cons of specific actions before selecting a course of action. This provides students the opportunity to hear a variety of thought processes from their colleagues as the group moves towards consensus on how they would address a scenario.

The second set of experiences deals with tasks that are typically performed in a school such as budget building, personnel selection, strategic planning, etc. Site-based groups design a school and perform these leadership and management experiences. This simulates the approach that is recommended when they become an educational leader.

The final component to the site-based experiences is for the group to engage in reflective inquiry. This reflective inquiry addresses the " 3 P's." The first 'P" involves thinking about the people involved in the activity, such as students, teachers, parents and other stakeholders and the influence they exert on the activity. The second "P" is reflecting on the implications for the position of the principal-ship. The final "P" is reflecting on the impact that the activity has on the individual/leader - personally and professionally. Reflective inquiry provides the student an opportunity to engage in introspection, a detailed mental self-examination of feelings, thoughts, and motivation [13].

In essence the goal of the site-based decision making group is to model and stress the importance of engaging and utilizing the talents of people in the decision making process. The mantra becomes "those impacted by a decision should have the opportunity to affect the decision."

\section{Student Reaction to the Process}

Students are engaged in collaborative activities throughout the online principal preparation program. As one goal of the program is to help students develop leadership skills in collaboration and cooperation, a student reflection on this process is included as part of the coursework. Student responses were analyzed and organized by theme. The themes that emerged from these reflective pieces were 1) value of the ideas of others, 2) awareness of communication style 3 ) sensitivity to the feelings of others.

In reflecting on the opportunities provided for collaboration and cooperation within the course, students remarked on the ideas that were presented during the discussion and problem solving process. As one student commented, "I find this process very effective as there have been several times when a group member mentioned something I never even thought about mentioning." This exchange of ideas allowed these future school leaders to see the value of including others in the decision-making process and the likelihood that more options can be presented in the collaborative process than by a single leader.

Students also became very aware of both communication style and the importance of clear communication. A student noted that communicating in the online environment will make you step back and evaluate your role in communication and how your message is received, which will open your eyes to the depth of communication and all the factors involved.

Another student added that listening skills are improved.

"This may seem odd, but I really feel that by working online you are forced to listen to others ideas and build relationships with people you wouldn't normally have to do in a regular classroom, and that helps to stimulate growth in the mind of soon to be leaders."

A collaborative culture is dependent on clear communication. Having to express ideas in written form and then give feedback to the ideas of others created a need for effective communication. As students presented ideas and read feedback from their peers, it quickly became obvious that some communication was being misunderstood. This required a careful review of the information's presentation and a second attempt to clarify the intent of the message. Gradually over the course of the program, communication became less ambiguous.

A final theme that emerged from the reflections was a need to always be sensitive to the feelings of others. Students served as peer-reviewers in the action research project and found it quite difficult to give constructive feedback. As these future leaders will soon be charged with evaluating teachers and providing guidance on areas that need improvement, learning to work collaboratively to find ways to improve areas of deficiency is critical. One student remarked,

"Writing is intimate and sharing your writing is definitely a way to get to know someone. I really, really do not like reading other student's papers unless they are well written. I have seen some poor examples of writing and I have also seen some good examples. Individuals are sensitive about their work so the initial critiques are difficult however everyone in my group learned to realize the value of having another set of eyes view their work."

This excerpt of one student's reflection is an excellent example of the collaborative culture that develops through these activities. Students work together to insure success for all. They recognize it is not easy to take or give suggestions for improvement, but the ultimate outcome is improved through the process.

\section{CONCLUSION}

Online leadership preparation programs are faced with 
developing the "soft skills" of leadership in an environment that is quite unlike that in which the leaders will actually function. By developing the value of collaboration and cooperation within the online environment, future leaders have the opportunity to instill the habit of valuing the ideas of others.

The process of creating a collaborative culture in an online environment builds across semesters. Students begin with small group analysis of real life school issues, move to creating an action research project that requires peer review, and culminate as a school-based team. In each step of the process, collaborative skills are increased and refined.

It is possible to intentionally teach the collaborative process along with other "soft skills" needed for effective leadership. However, it must be a clear thread that connects an entire program of study. Professors must also work collaboratively to build this environment. Students of leadership do not come to a program with the skills to collaborate and work cooperatively. In fact, traditionally graduate programs have a competitive environment rather than a cooperative one. In addition, people who seek leadership positions tend to be individuals with great confidence in their own abilities. As one student noted.

"This program draws strong willed people that strive to become leaders in their profession. This can lead to people used to being right all of the time, now struggling to work with others. You learn to rely on the help of others to find good solutions. You will learn that it is not all up to you."

The challenges students face in interacting in a online environment enhance the development of a collaborative culture. Students reach out to others for assistance with technology, understanding assignments, and support. The stage is set to develop collaborative skills that will be essential to success as a leader. For many students this learning adventure is not an easy one, but in their final reflections, it is clear that all value the journey.

\section{REFERENCES}

[1] K. Leithwood and P. Sieegers, "Transformational school leadership: Introduction," School Effectiveness and School Improvement, vol. 17, no. 2, pp. 143-144, Feb. 2007.

[2] W. Hoy and B. Brown. "Leadership behavior of principals and the zone of acceptance of elementary teachers," The Journal of Educational Administration, vol. 26, no. 1, pp.23-38, Jan. 1988.

[3] K. Leithwood, "The move toward transformational leadership," Educational Leadership, vol. 49, no. 5, pp. 8-12, 1995.

[4] C. Brungardt, "The intersection between soft skill development and leadership education," Journal of Leadership Education, vol. 10, no. 1, pp. 1-22, Winter, 2011.

[5] C. Dwyer, C. Millett, and D. Payne, A culture of evidence: postsecondary assessment and learning outcome-recommendations to policymakers and the higher education community, Princeton, NJ: Education Testing Service, 2006.

[6] D. Goldman, The Emotionally Intelligent Workplace, San Francisco, CA: Jossey-Bass, 2007
[7] N. Dana, Leading With Passion And Knowledge: The Principal As Action Researcher, Thousand Oakes, CA: Corwin, 2009.

[8] M. Cochran-Smith and S. Lytle, "Relationships and knowledge and practice: Teacher learning in learning communities," in Review of Research in Education, A Iran-Neland and P. Pearson, Eds, Washington, DC: American Educational Research Association, vol. 24, 1999, pp. 245-305.

[9] S. Bethel, A New Breed of Leader: 8 Leadership Qualities That Matter Most In The Real World, New York: Berkley Books, 2009.

[10] C. Christensen and A. Hansen, Teaching and the Case Study Method, Boston: Harvard Business School, 1987.

[11] M. Goldsmith, What Got You Here Won't Get You There, New York: Hyperion, 2007.

[12] K. Cotton, School Based Management: School Improvement Research Series, Andover, MA: Northwest Regional Educational Laboratory, 1991.

[13] R. Sherman, Peggy Gill, and Cynthia Sherman, "Soup du jour and so much more: A model for school leader preparation," Journal of Scholarship \& Practice, vol. 4, no. 3, pp. 5-10, Fall, 2007.

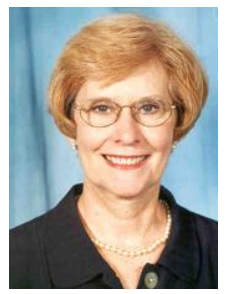

Peggy B. Gill was born in the United States in 1946 She received her Bachelor of Arts Degree in history and English from Stephen F Austin State University in Nacogdoches, Texas, USA in 1969, her Master of Education in special education from Texas Women's University in Denton, Texas, USA in 1974 and her Doctorate of Education in educational leadership from Stephen F. Austin State University, Nacogdoches, Texas, USA in 2000

She has worked as a classroom teacher, diagnostician, director of alternative school and principal of special needs school. She is currently professor at the University of Texas at Tyler. Her research interests include online learning, leadership, and rural education.

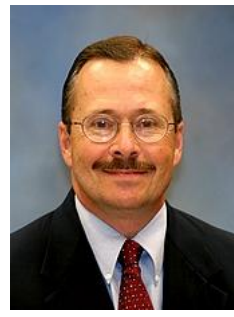

Ross B. Sherman was born in the Unites States in 1952. He received his Bachelor of Science Degree in elementary education from Temple University in Philadelphia, Pennsylvania, USA in 1973 . He received his Master of Education in Administration and Supervision from Temple University, Philadelphia, Pennsylvania, in 1978. He received his Doctor of Education in Administration and Supervision from the University of Houston in 1986. He has worked as a classroom teacher, assistant principal, principal, professor and department chair. He is currently the acting Dean of the College of Education and Psychology at the University of Texas at Tyler. His research interests include, the principal-ship, online learning and issues of social justice.

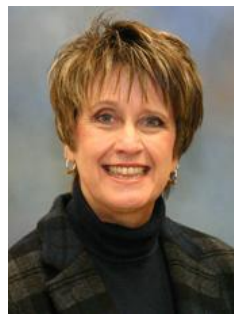

Genie B. Linn was born in the United States in 1950 Dr. Linn received her Bachelor of Arts in English from Texas Woman's University, Denton, Texas USA in 1973. She received her Master of Arts in English from the University of Texas at Tyler, Tyler, Texas USA in 1990. She received her Doctor of Education in educational leadership from Stephen F. Austin State University, Nacogdoches, Texas USA in 2001.

She has served as a classroom teacher, educational consultant and is currently an Associate professor of educational leadership at the University of Texas at Tyler, Tyler, Texas USA. Her research interests include action research, qualitative inquiry and narrative research. 